\title{
GENDER, LANGUAGE AND INDIAN REALITY TELEVISION: LOCATING SOCIAL STEREOTYPES AND LINGUISTIC SEXISM
}

\author{
SOHAIB ALAM \\ Department of English, College of Sciences and Humanities in Al Kharj \\ Prince Sattam bin Abdulaziz University, Al-Kharj, 16278 Saudi Arabia \\ E-mail address: s.alam@psau.edu.sa \\ ORCID: https://orcid.org/0000-0002-9972-9357 \\ SHAFEY ANWARUL HAQUE \\ Centre for Women's Studies \\ Aligarh Muslim University, Aligarh, Uttar Pradesh, 202001 India \\ E-mail address: sahaque@myamu.ac.in \\ ORCID: https://orcid.org/0000-0001-7981-5998
}

\begin{abstract}
Aim. The reality genre has gained much popularity in the last few years across the globe. In India too, this genre has reportedly surpassed other genres in recognition and acceptance. Although its format and content provoke controversies at both social and academic level, its mass appeal is constantly increasing. The study examines gender and language issues in Indian reality show Bigg Boss. While keeping in view the format and claims of the genre, the study observes how the housemates negotiate with their real selves and shape their language practices under thorough surveillance. The influence of neoliberalism on the society, culture and identity has been very much discussed: the paper attempts to highlight how this transition in gender identity is depicted in a show involving non-actors and common people.

Concept. For the purpose of the study, scripted transcription of Bigg Boss (Season 11) has been used, wherein all the episodes have been carefully watched, and detailed notes were prepared for the analysis. Housemates' language practice, voice pattern and preference of words and statements have been observed.

Results and conclusion. The study finds that game reality show Bigg Boss substantially adheres to social stereotypes and standards and while doing so, it also imitates the language practice prevalent everywhere. The active participation of women in the show is visible; however, while exhibiting their true self, sometimes gender prejudice embedded deep inside also comes out, which is particularly frequent in the case of men. The study concludes that as a globally acclaimed genre, reality show, like other genres, is very much commercialised and consumer oriented.

Originality. A number of studies related to reality shows have been conducted, but in Indian context, this genre has been inadequately explored. Also, it is very difficult to
\end{abstract}

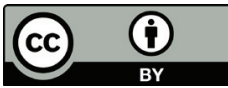


find studies focusing on any specific season of an Indian reality show, so the present study might be considered one of the primary works on this subject, which aims at making some significant academic contribution related to this genre.

Key words: reality television, gender, language, social standards, adherence, audience perception

\title{
INTRODUCTION
}

\begin{abstract}
A fter economic reforms of 1991 in India, advancement in the communication technologies began at a great pace. A massive expansion in the electronic media occurred and transnational communication began which gave way to a number of entertainment channels (Mathai, 2015). With the advent of various media enterprises, numerous appealing programmes hit the television screen and transformed the lives of the audience across the country. This reposition turned India into a mature broadcast market. Among various genres, reality shows also started flourishing in India. As far as the emergence of this format in India is concerned, it cannot be said that reality shows came to India after 1991: back in 1970s, the period when both documentary films and full-length colour films were prospering, Bournvita Quiz Contest (BQC) appeared, which was the first reality game show. However, after the economic reform when a number of television networks entered into the market, this show, in 1992, became the first to be featured on any regional network except Doordarshan, which was enjoying the monopoly before the reforms.

At the global level, it was the time when the first generation of the reality television was prospering, especially in the US and the UK, where deregulation has already occurred in the 1980s (Kavka, 2012). But for India, except BQC, the genre was new and like other countries, where reality shows were being produced to cut the cost of production (Kavka, 2012), India too began introducing new formats.
\end{abstract}

\section{LITERATURE REVIEW}

Early nineties saw a massive shift which occurred after a number of reality game shows appeared. This venturing with the reality genre continued and with the beginning of the $21^{\text {st }}$ century, the reality game show Bigg Boss followed, with an entirely new and sensational format, produced by Endemol Shine India. Based on a Dutch reality game show Bigg Brother, this show keeps its contestants, called 'housemates' under complete surveillance in a specially constructed house for a specific time period, usually three months. In a short span of time, reality television gained utmost popularity and acceptance across the globe. Even media scholars like Misha Kavka or Mark Andrejevic shifted their focus to understand this genre, its style and format, intricacies and influences. While noticing the inclination of the viewers towards the genre, they began studying its socio-cultural significance 
and analyse the pattern and behaviour of the contestants and its compliance to the social norms and standards. Similarly to other television genres, scholars argue that reality shows also promote the conformist ideology reinforcing the moral and ethical boundaries, therefore not going beyond the social construct. Like Miller insists that reality television is a viable genre and the ideologies, values and myths incorporated in it are reflective of current social trends and behaviour (Miller, 2007). This argument is based on John Fiske's idea of realist narrative that, "classic realist narrative and its preferred reading strategy try to construct a self-contained internally consistent world which is real seeming" (2011, p. 131).

Furthermore, while observing social acceptance of this relatively new genre, critics argue that the popularity of reality television is a sign of cultural decline (Holly, 2005). While making such a harsh argument, they take into consideration all the aspects, including its format, content, behaviour and language of the housemates, etc.

The present study intends to look into the reality genre through its gender and language aspects. In order to understand the linguistic representation in the said genre, a general apprehension of television genres and their depiction of language and gender are necessary, because they are, to a certain degree, interlinked. Even reality shows have their roots in documentary and there are apprehensions that the rise of tabloid news and decline of documentaries pushed reality genre (Hill, 2005). Hence, understanding of linguistic aspects and portrayal in media would surely help locate the same in reality genre.

Examining language pattern in media, especially television genres, predominantly suggests that adherence to social norms and stereotypes related to gender and language is very common. Language being one of the important means of conveying social and cultural values plays key role in stimulating gender roles (Holly, 2005). During the process of socialisation, people learn about their culture, beliefs and values through the medium of language (Pavlikova, 2021). Media primarily attempts to highlight the socially constructed gender roles and while doing so, it also imitates the linguistic style and pattern prevailing in the society. However, media scholars believe that gender differences in the depiction of language has comparatively subverted; earlier conformance to the social standards had been very frequent. One of the language aspects which scholars highlighted is the use of 'powerful' language, which indicates "having more speaking turns, getting the first and last word in conversation, interrupting more and giving much advice" (Pavlikova, 2021). Lauren and Dozier in their study based on an American television show, argue that viewers find men using more powerful language than women while talking because of their strength in numbers (1995); however; when studied according to the individual characters, they find that both men and women get similar chances.

Another study based on American news shows, observing linguistic behaviour of men and women, highlight what content and sentences they choose to speak. The study reveals that women use simpler language and shorter sen- 
tences, and speak more about their social and sensory processes, whereas men try to deliver more knowledge and information by using complicated and long sentence structure (Brownlow, Rosamond, \& Parker, 2003). However, in this detailed study, after analysing the language pattern at various positions which men and women held with similar roles and circumstances, researchers further argue that men and women speak similarly in general. This argument can be seen in contrast with some of the popular texts on language and gender where it has been stated that women have always and everywhere been measured against a similar linguistic ideal, constituted by such qualities as reticence, modesty, deference, politeness, empathy, supportiveness and cooperation, but a keen observation shows a complicated picture (Lakoff, 1975).

Albeit describing the issue of language and its depiction in media, some scholars look at it as a fundamental aspect of human representation as Raymond Williams say, "a representation of language is always a representation of human beings in the world" (Homes \& Meyerhoff, 2003). On the other hand, scholars also believe that anything which is associated with language is "systematically related to other areas of cultural discourse such as the nature of persons, of power, and of a desirable moral order" (Gal, 1995). In case of reality television, which is presumably unscripted and shows real people as contestants, the issues of gender and linguistic representation turns impenetrable. It happens because for actors, the sense of manipulation is, to a great extent, unambiguous, but when non-actors appear onscreen, the matter of performance, alteration or screen-writing becomes ambivalent. Audience also watches them while keeping in mind their spontaneity and originality.

But there are, for a number of reasons, some strong arguments against the authenticity and reality of the reality genre. Since the housemates are kept under rigorous surveillance, Regan Fox, in his book Inside Reality TV: Producing race, gender and sexuality on Big Brother, says that the reality show Big Brother is very much based on Jereny Bentham's circular prison and the panopticon, and the idea of surveillance which Michel Foucault explores in his book Discipline and punish using the former's idea of monitoring (2019). The author further suggests that, like prisoners under surveillance police their own action, housemates in Big Brother also remain conscious about their actions and representations onscreen (Fox, 2019). Chung Ho-ying Holly, on the other hand, states that such shows are heavily edited and only controversial and intriguing scenes are put on air (2005). They rest their argument on the contract, which the participants of another reality show Survivor are asked to sign, that says:

Producer may depict, portray me and my Life Story either accurately or with such liberties and modifications as Producer determines necessary at its sole discretion for the purposes of fictionalisation, dramatisation or any other purposes including without limitation to achieve a humorous or satirical effect. (Holly, 2005, p. 45)

All such arguments reflect that reality show, at least academically, should be treated as carefully exhibited and edited, if not scripted. The authors would 
discuss reality show here in the same light and then examine the issues of language and gender. And when we look at it further, we observe that there is coherence between the language of the housemates and social standards. For instance, while discussing Shilpa Shetty and Jedd Woodie's event in Celebrity Big Brother $5^{\text {th }}$ season, Roselyn George and Heather Mendick note that the tussle between the two over the language, when the former told the latter that she should "fuck off home" and "she can't even speak English properly." This gave rise to the racism debate and obscured the issues of language, but when Shilpa called Jade and other housemates Jo and Danielle "witches with a capital B" appeared to various commentators as an intersection of race, class and gender (George \& Mendick, 2010). Also, when the social stereotypes are followed, it has been argued many times that men show positive attitudes and assertiveness, whereas women look vulnerable and dependent, so the role of language in observing attitude and skills becomes very apparent.

\section{AIMS AND OBJECTIVES OF THE STUDY}

While keeping in mind the definition and nature of the reality genre, the study observes how conventional approach to gender is contested through linguistic behaviour of the housemates. Since it has been discussed at large that reality genre boosts about the 'reality' factor of such shows, the present study would try to deconstruct the notions of masculinity and femininity and their representations to stimulate the idea of men and women's language amongst the audience. The paper aims at analysing the language and gendered perspectives of the reality genre to show how media promotes the conventional but dominant discourse of gendered language through entertainment. While examining the language pattern, the paper would keenly inspect the interaction between male and female housemates, their word and sentence preferences, intonation and articulation.

Since its beginning, the reality genre has raised controversies because of its content and language, for promoting voyeurism and acting as a significant tool in social and cultural downfall; consequently, the paper intends to highlight how, despite such polemics, it continues to attract viewers, especially through the language used by the inmates to build gendered narratives. Gender representation on television usually focuses on some familiar and well-established social norms and standards related to the behaviour of men and women, but in other genres where actors and editors are involved, the questions of gender dynamics appear accessible and well-defined. However, in this seemingly new genre, it looks complicated, as discussed earlier; hence, the paper would try to see how reality shows approach and challenge the common tales of gender representation.

Moreover, there has been much discussion related to the role of television in neoliberal cultural transformation. Anna Cooper (2019) in her paper "Neoliberal theory and film studies" says: 
Cinema has a unique capacity to dramatize, embody, and/or reimagine various neoliberal cultural transformation, or alternatively to resist them. Of course films show people, social identities, communities and spaces impacted by neoliberal ideology- It would be hard not to, given neoliberalism's seemingly boundless dominance - and films can clearly give insights into what these look like and how such entities are being transformed. (Cooper, 2019, pp. 265-277)

Keeping this argument and the neoliberalism's influence on the society, culture and identity in view, the paper would discuss how the transitions in gender identity are depicted in a show highlighting non-actors under thorough surveillance.

\section{METHODOLOGY OF THE STUDY}

The show chosen for this study is Indian reality show Bigg Boss (Season 11). It was aired in 2017 on Colors TV from October $1^{\text {st }}, 2017$ to January $17^{\text {th }}$, 2018, consisting of 106 episodes. This season brought nineteen participants, including celebrities and common people, in one especially constructed house at Lonavala, $96 \mathrm{~km}$ to east of Mumbai, India, aloof from the rest of the world, with cameras around to keep constant watch on them.

The housemates in the chosen season were Hiten Tejwani (44) - TV/film actor, Luv Tyagi (25) - model and engineer, Mehjabin Siddiqui (37) - housewife, Lucinda Nicholas (26) - Australian model and actress, Sabyasachi Satpathy (41) - TV host and dancer, Sapna Chaudhary (27) - dancer, Shivani Durga (43) - self-styled God woman, Priyank Sharma (24) - dancer and model, Beenafsha Soonawala (22) - VJ and model, Akash Dadlani (24) - rapper, Jyoti Kumari (20) - student, Bandgi Kalra (25) - model and engineer, Arshi Khan (29) - model and actress, Hina Khan (31) - TV actress, Puneesh Sharma (35) reality TV star, Vikas Gupta (31) - producer, Shilpa Shinde (41) - TV actress, Dhinchak Pooja (25) - singer, Zubair Khan (31) - filmmaker.

The season continues for 105 days and, besides daily activities, housemates perform in various tasks assigned either by Bigg Boss or by any other guests. They are evicted one by one on the basis of audience poll weekly, and the one with highest number of votes at the end of the season turns up as winner.

In order to study the linguistic practices of the housemates, script transcription has been used, where all the episodes of Season 11 have been watched back and forth and detailed notes, according to the days spent, regarding male and female interaction, language practice and voice pattern, prepared. Excerpts would also be included in support of the argument while discussing the analysis.

\section{DETAILED ANALYSIS OF THE STUDY}

Bigg Boss 11 begins with the host giving all the housemates a grand welcome to the house and introducing them to the audience. After the big reception, as soon as housemates enter the house, their performance begins, and voting 
line opens for the audience. On the first day only, Zubair comments on Arshi, keeping her skimpy outfits and strident nature in mind, ye ladki bohot se logo ko khwar karna chah rahi hai jisme ek mai bhi hun ("This woman wants to lead astray so many people and I am one of them"). The word khwar ("to lead astray or insult") here, which Zubair puts stress on, demonstrates the diffident nature of patriarchal structure where such objectionable terms are employed for women like Arshi. It shows one aspect of traditional Indian society where men tend to decide how women should dress and behave, rather regulate them, and if women reject such narratives of subjection and strongly assert their choices, like Arshi does by saying Ye to tariqa hai mera ("This is my way of living"), they take it as disdain and disgrace. It can be seen again when hen the duo enter into an argument, Zubair shouts, abe laanat hai tere pe, aurat zaat pe kalank... do kaudi ki aurat, two rupees aurat ("Shame on you, you are a disgrace to womanhood, you characterless women"). His comment has been taken as misogyny by the audience, as some news reports stated (Vineeta Kumar, 2017). Even, some guests in the house (Shweta singh (news anchor), Malishka (RJ), Pritam Singh (actor)) in their discussion about the season noted that Zubair's comments reflect his patriarchal mindset."'

At other instance, Vikas refers Shilpa also as "disgrace to womanhood" just because she provokes him and he falls short of tolerance. This is how patriarchy functions in the society; in their attempts to rule women, they classify them, based on their outfits, behaviour and attitude, into "good women" and "bad women" and also presume their role at home and outside home. This is not necessarily done by men, women too count on this. For instance, when Beenafsha is washing utensils in the kitchen, Shilpa comments on her, dekho bhai log aisi ladkiyan bhi bartan dho sakti hain ("Look people, such girls can also wash utensils"). Again, the term aisi ladki ("such girls") is also a part of the same oppressive structure restrains choices. Andrea Dworkin says, "Being female in this world means having been robbed of the potential for human choices by men who love to hate us. One does not make choices in freedom. Instead, one conforms in body type and behaviour and values to become an object of male sexual desire, which requires an abandonment of a wide-ranging capacity for choices" (Oyler, 2019).

As pointed above, women as part of the patriarchal society too, adjust according to their norms very conveniently, as Bell Hooks say, "Patriarchy has no gender" (2014). It is so embedded that men take humiliating women as their right, and sometimes women not only ignore, but also promote this appalling idea. For example, once Sapna reveals that she asked Shilpa to tell Akash to not comment on women, she replies, ladka hai karega ("He is a man, he will do it"). The question is why reality shows depict such coercive belief. Are they trying to prove their claim of being "real" or showing the reality of the real world? In the show, they humiliate body-shame and vilify each other. Using derogatory remarks and abusive language is very common by both male and female housemates for each other, though abuses are always beeped. Arshi comments on Hina, Patli Dolly Bindra, Zubair ki biwi ("skinny Dolly Bindra, Zubair"s wife") 
and aur ye aurat itni badi \{beep\} hai, itni badi \{beep\} hai, she is a \{beep, ye jo hai zubair ki \{beep\} hai ("This woman is so \{beep\}, she is so \{beep\}, she is Zubair's \{beep\}"). Hina, at other instance returns this to Arshi by saying, na shakl hai na soorat, us par se drum jesi dikhti ho ("You've got no good looks or beauty, moreover your body looks like a drum"). Dolly Bindra was a former Bigg Boss contestant, with heavy physical appearance, very blunt and loud behaviour, because of which she had been in controversy while being in the house. Both of them shame each other for their physical appearance; Arshy tries to compare Hina and Dolly on grounds of latter's appearance and loud behaviour which is usually not expected from women in Indian society, rather it denotes they are not civilised or well mannered, and Hina in response, too sling off at her body. And all that which has been beeped are abuses where usually they use women as prefixes which is, as stated very common all around and this depiction reflects how media approaches socially acceptable norms and behaviour, and the notions of gender equality and women empowerment.

Throughout the show, one can find numerous examples of such discomfiting remarks from both male and female members of the show. Hina informs other housemates about Puneesh's comments on Shilpa and Mehjabeen, and then latter reacts with equal repellence. Puneesh says, ek gora bhoot, ek kala bhoot ("One fair bitch, one dark bitch") and Mehjabben refers to him as kala bandar ("black monkey"). Puneesh shouts at Hina during an argument and calls her badzaat ladki ("Rascal girl"). It is also evident form their frequent ridiculing of someone's profession especially women. For instance, Sapna is a dancer and Arshi calls her naachne wali (colloquial slang for someone who dances). In India, dance is a popular form of art but dancers do not get respect for their art or passion. Manjari Chaturvedi, a Sufi Kathak dancer says, "Nachnewali, nachaniya, tawaif, mujra (colloquial slangs) these are all terms that are used to slam a woman performer. The irony is that similar men performers are given respect whereas women are subjected to ridicule. It's all patriarchy driven; the idea is to show women her place. And while we talk of women's rights, the most elite educated people fall prey to using these terms easily" (Swati Chaturvedi, 2020).

During other arguments, Arshi refers to Sapna as, kachra bunne wali... badbudaar aurat... shakl se baas maarti hai ("garbage cleaner... stinky woman... even your face smells unpleasant"). It clearly shows how commonly used slangs are copied in the show to make it sensational and attractive. There are instances where even male housemates are humiliated for their physical appearance like Puneesh comments on Priyank: Plastic ki body hai iski, choose jesi chukni shakal hai iski, ladki hai bilkul ye ("He has got a body made of plastic. With his clean shaven face he looks like a chicken. He looks like a girl"). If we look at this issue off screen, both men and women become victims of body shaming; though women are humiliated more, one may conclude that body shaming is a serious concern for both, yet at varying levels. However, both male and female housemates use these words, they frequently oppose and nominate others for being disrespectful: Arshi is nominated by almost all of them for her behaviour and 
language. Irrespective of their attitude, they get audience vote and try harder to stay in the house till the end. In case of LGBTQ, the situation is also worrisome. The claim behind their representation in reality television is to give them equal space and respect but housemates' style of addressing one another makes it contradictory. Though they try not to discriminate and ridicule, the words they use often reveals social tendency to deride one another using homophobic slurs, like Arshy calls Vikas, a gay housemate, gur ("jaggery") and meetha ("sweet"). Although the show host criticizes and warns housemates for their behaviour, they barely care, and this makes the show format very ambigous.

The objectification of women has been a fashion in patriarchal societies, and men often take pride in presenting women, through their language, as an object. Its depiction in reality show is also perennial; for example, Sapna tells Priyank about Puneesh's comment on Bandgi, though they have feelings for each other, that: aisi ko to mai roz club me chod ke aata hun, ise to mai chod ke bhi na aaun, ye to bas game ke liye hai ("I dump girls like her in the club daily. At her I don't even have to see. I am with her for the purpose of game only"). Puneesh's comment about Sapna's profession also reveals similar sense of chauvinism besides degrading her dance. Hina tells Priyank about his comments that, show khatm hone $k$ baad wo log aise hojate hain ke bas chaiye to chaiyye, ni milegi to utha ke lejayenge ("After her dance performance ends, audiences go crazy and force her to go with them, and if they don't get any chance, they would pick her and leave"). In traditional Indian society, treating a woman in such a way is more than common and the issue of depiction on television a little obscured. This indicates two features while treating a person as an object, i.e., 'ownership' and 'denial of subjectivity' which means the possession of a person as one's own and taking a person as something whose emotions and feelings do not matter, respectively (Nussbaum, 1995).

Although objectify women, men at times accuse them of objectifying men as well: for example, Akash tells Shilpa when the latter complains to him about not supporting her, tu to bas mujhe use kar rahi thi ("You were just using me"). It can be taken as male ego, when they do not find any road to escape; they put blame on the other gender. It also reveals how language in a male-dominated society is being used to suit the interest of the oppressor. This male ego is also manifested when a woman tries to suggest something to or guide a man, which he finds as her dominance: for instance, when Bandgi tries to tell Puneesh not to talk in front of Hina because, according to her, she exaggerates things and he should be careful, to which Puneesh reacts, Mujhe jo karna hai karunga, jise exaggerate karna hai kare ("Don't scold me, don't talk to me in louder voice. I will do what I want to do, let her exaggerate").

While representing social norms, this show at times makes it challenging for housemates and viewers, irrespective of their gender, to decide what comes first: game or moral values. Beenafsha and Hiten refuse to pee in their trousers onscreen by saying that they cannot do this on national TV, during the captaincy task where they are competing along with Puneesh and Puneesh decides 
to pee in his pant onscreen to win the task. They have to maintain their balance while cycling and drinking water when the buzzer rings, and the one who stays for the longest, wins. Puneesh plays spiritedly; Sapna calls him besharm ("shameless"), and adds, maa baap bhi sochte honge kesi besharm aulaad paida ki hai ("His parents must be thinking what a shameless child we've got"). This shows how values are embedded; beyond all patriarchal norms, there are unspoken rules which even men cannot surpass. And if they do not abide by those rules, they become shameless. But all such behavioural standards are so complicated that it is very difficult to extricate them.

The show encompasses numerous instances, including those discussed above, and the use of language is central to their behaviour and attitude. Their linguistic practices manifest how acceptance of gendered norms and stereotypes are shown, and this leaves the question related to nature of the show unanswered. No matter whether it is real or unreal, it substantially promotes social stereotypes.

\section{CONCLUSION}

The analysis shows that the issue of gender and language in reality television is substantially similar to other genres, especially soap operas, where women are portrayed as pitiable, acquiescent or dependent on men. They are not represented beyond divisive binaries and stereotypical gender roles. In the case of reality television, however, both men and women are represented as independent individuals and players, but the stigma associated to women gets on with them - men's behaviour and language carries those stigma, and sometimes women enforce it on themselves. The role of language in communicating stigma and stereotypes is pivotal. Since it is the primary means to transfer ideology and culture, its role in conveying conventional and sometime unjust norms and beliefs related to a gender, as Nayantara Dutta writes in her piece titled "The Subtle Ways Language Shapes us," published by BBC:

The gender structure we are speaking will have the effect of making us more or less aware about gender. With gendered language, we have to think of gender while conjugating a verb or using a noun, so it is possible that gender-based stereotypes and gender power structures are more likely to influence our thoughts and opinions about the sexes. (2020)

Thus, it can be concluded that Indian reality show Bigg Boss, to attract viewers, adheres to the social norms and standards to create a sense of false consciousness. The language practice in the show reveals that, like other genres, these shows are also encouraging through representation of body shaming, abuses, slurs and so on, the dominant but prejudiced narratives. 


\section{ACKNOWLEDGEMENT}

This publication was supported by the Deanship of Scientific Research at Prince Sattam bin Abdulaziz University, AlKharj, Saudi Arabia.

\section{REFERENCES}

[1] Brownlow, S., Rosamond, J. A., \& Parker, J. A. (2003). Gender-linked linguistic behaviour in television interviews. Sex Roles, 49(3/4), 121-131.

[2] Chaturvedi, S. (2020). No shame in art. Retrieved January 15, 2021 from https:/ / www.hindustantimes.com/tv/no-shame-in-art/story C2SmuCZkn5ozYGlSkWUBtJ.html

[3] Cooper, A. (2019). Neoliberal theory and film studies. New Review of Film and Television Studies, 17(3), 265-277. DOI:10.1080/17400309.2019.1622877

[4] Dutta, N. (2020). The subtle ways language shapes us. BBC. Retrieved January 18, 2021 from https:// www.bbc.com/culture/article/20201006-are-some-languages-more-sexist-than others

[5] Fiske, J. (2011). Television culture ( ${ }^{\text {nd }}$ ed.). London and New York: Routledge.

[6] Fox, R. (2019). Inside reality TV: Producing race, gender and sexuality on Big Brother. Routledge: Taylor \& Francis Group.

[7] Gal, S. (1995). Language, gender and power: An anthropological review. In: Kira Hall \& Mary Bucholtz (Eds.), Gender articulated: Language and the socially constructed self (169-182). London: Routledge.

[8] Holly, C. (2005) Language and gender representations in the television reality show Survivor: The Amazon. [Master's thesis, University of Hong Kong].

[9] Holmes, J., \& Meyerhoff, M. (2003). The handbook of gender and language. Blackwell Publishing.

[10] Kavka, M. (2012). Reality TV. Edinburgh University Press Ltd.

[11] Kumar, V. (2017). Misogyny and elitism rule Bigg Boss 11 house. Arshi Khan called '2 rupees women'; Shilpa Shinde shamed for bad English. Inuth. Retrieved January 8, 2021 from https://www.inuth.com/entertainment/bollywood/misogyny-and-elitism-rule bigg-boss11-house-arshi-khan-called-2-rupee-woman-shilpa-shinde-shamed-for-bad english/

[12] Lakoff, R. (1975). Language and woman's place. New York: Harper Torch Books.

[13] Lauzen, M. M., \& Dozier, D. M. (1999). Making a difference in prime time: Women on screen and behind the scenes in the 1995-1996 television season. Journal of Broadcasting and Electronic Media, 43(1), 1-19.

[14] Mathai, S. (2015) . Indian television in the eras of pre-liberalisation and liberalisation. Media Watch, 6(2), 255-268.

[15] Mendick, H., \& amp; George, R. P. (2010, August 1). Language, power and reality TV: the dynamics of race, class and gender in the UK Big Brother Jade-Shilpa row. Retrieved January 1, 2021, from http://research.gold.ac.uk/id/eprint/4109/.

[16] Miller, A. F. (2007). Cultural values, narratives and myths in reality television. [Doctoral dissertation, University of Southern Mississippi].

[17] Nussbaum, M. (1995). Objectification. Philosophy and Public Affairs, 24(4), 249-291.

[18] Oyler,L. (2019). Theradical style of Andrea Dworkin. New Yorker. Retrieved January 6, 2021 from https://www.newyorker.com/magazine/2019/04/01/the-radical-style-of-andrea-dworkin

[19] Pavlikova, M. (2021). Kierkegaard's controversy with 'The Corsair'. XLinguae, 14(3), 222-229.

[20] Teaching to transgress: Bell hooks returns to the New School. (2014). Retrieved January 12, 2021 from https:/ / blogs.newschool.edu/news/2014/10/bellhooksteachingtotransgress/ 